\title{
Umbilical coiling index and its association with perinatal mortality and morbidity in a low resource tertiary care hospital of northern Karnataka - a prospective observational study
}

\author{
Aruna Biradar, Shreedevi Kori, Neelamma Patil, SR Mudanur
}

\begin{abstract}
Corresponding author: Dr Shreedevi Kori, Associate Professor, Department of Obstetrics and Gynaecology, BLDE (Deemed to be) Shri BM Patil Medical College Hospital Research Center, Vijayapura, Karnataka, India; Email - Shree_kori@yahool.com
\end{abstract}

Distributed under Attribution-Non Commercial - Share Alike 4.0 International (CC BY-NC-SA 4.0)

\begin{abstract}
Objectives: The aim of the study is to determine the association between the length of the umbilical cord and the coiling index with the perinatal outcome. Methods: It's a prospective study of 600 pregnant women from 28 to 40 weeks of gestational age. The umbilical cord length was measured from the placental insertion point to the foetal attachment of the cord. The coiling index was calculated by dividing the number of coils divided by the length of the cord. The coiling index was measured at the time of cord clamping in both vaginal and caesarean section. The cases were divided into three groups i.e., normocoiled, hypocoiled and hypercoiled and their association with the perinatal outcomes were assessed. Results: The mean umbilical coiling index(UCI) was found to be $0.57 \pm 0.18 \mathrm{coils}$ per $\mathrm{cm}$. Abnormal foetal heart patterns, oligo and polyhydramnios, hypertensive disorders, placental abruption, gestational diabetes mellitus, caesarean section rates, low birth weight and intrauterine foetal death had high correlation with hypocoiled and hypercoiled compared to normocoiled which is statistically significant (p-value of $<0.001$ ) in our study. Conclusion: Abnormal umbilical coiling index which is measured during both vaginal delivery and caesarean section is associated with adverse perinatal outcomes.
\end{abstract}

Keywords: UCI (umbilical coiling index), hypercoiled, hypocoiled, perinatology.

As said by Ian Donald "the baby's life hangs by a cord" 1, thus showing the importance of umbilical cord. It is an important part of the fetoplacental unit. So, any abnormality in this cord - like vasospasm, compression and knots of the cord may lead to foetal distress and intrauterine foetal demise ${ }^{2}$. Even the abnormal length of the cord is also associated with complications. Short cords are associated with a delay in the second stage of labour, irregular FHR, placental abruption, rupture of the umbilical cord, inversion of the uterus, birth asphyxia and cord herniation ${ }^{1}$. Long cords are associated with cord prolapse, torsion, true knot, the entanglement of cord around the fetus ${ }^{1}$. A mature cord at term measures around $50-60 \mathrm{cms}$ in length and $12 \mathrm{~mm}$ in diameter. The long cord is defined as $>100 \mathrm{cms}$ and short cord $<30 \mathrm{cms}$. There may be around 40 spiral twists in cord and prone for false knots and true knots ${ }^{1}$. Short cords are associated with adverse perinatal outcomes such as foetal growth restriction, intrapartum distress and risk of foetal

Received: $14^{\text {th }}$ March 2020. Accepted: $25^{\text {th }}$ April 2020.

Biradar A, Kori S, Patil N, Mudanur SR. Umbilical coiling index and its association with perinatal mortality and morbidity in a low resource tertiary care hospital of northern Karnataka - a prospective observational study. The New Indian Journal of OBGYN. 2020; 7(1): 10-5. 
death ${ }^{1}$.

The umbilical cord is protected against compression by Wharton's jelly, amniotic fluid, helical patterns and coiling of vessels. The origin of the umbilical cord is unknown. The most mysterious character of the human umbilical cord is the twisted or spiral course of its component blood vessels. Mathematically speaking, vessels of the cord are wound as cylindrical helices, rather than spirals, but both terms are used interchangeably to avoid confusion ${ }^{3}$. The coiling of the umbilical vessels develops as early as 28days after conception and is present in about $95 \%$ of foetuses by 9 weeks of conception. The helices may be seen by ultrasonographic examination as early as by 10 weeks of gestational age ${ }^{3}$. In 1954, umbilical coiling was first quantified by Edmonds, who divided the total number of coils by umbilical cord length in centimetres and called it "The index of a twist", but later Strong et al named it "The umbilical cord index" ${ }^{4-7}$.

Despite improved antenatal care, safety during surgery and use of modern monitoring with ultrasound, doppler and intrapartum foetal monitoring, cord complications remain one of the major unavoidable causes of foetal death compromising umbilical blood flow to a degree sufficient to cause severe hypoxia and death of the fetus. Abnormal cord parameters associated with a high rate of asphyxia during delivery, non-reassuring foetal status, respiratory distress, foetal growth restriction and thus needing interferences (instrumentations/operative) during delivery ${ }^{8,9}$.

The total number of coils is between $0-40{ }^{10}$. At term, the umbilical cord measures an average of $55 \mathrm{~cm}$ (the usual range is $30-100 \mathrm{cms})$. The umbilical vessel's helical course is seen by 7 th week of gestation in about $95 \%$ of foetuses ${ }^{11}$. An umbilical coil is defined as one complete spiral of 360 degrees of umbilical vessels around each other. Sinistral spiralling (left side) is 4 to 8 times more common than dextral spiralling (right), a mixed pattern of spiralling is also seen. Whereas, in $2-5 \%$ of umbilical cords there may be no spiralling ${ }^{12,}{ }^{13}$. Many studies have shown that the normal pattern of coiling is at the rate of $5 \mathrm{~cm}$ equal to coiling index of $0.2 / \mathrm{cm},<0.1 / \mathrm{cm}$ is hypocoiled, $>0.3 / \mathrm{cm}$ hypercoiled ${ }^{11}$. A study by Chitra et al (2012) showed umbilical coiling index frequency distribution as follows: $<10$ th percentile: hypocoiled; 10th -90 th percentile: normocoiled; $>90$ th percentile: hypercoiled. The length of the umbilical cord increases throughout the pregnancy more so nearing term approximately at the rate of 3-6 $\mathrm{cm}$ per month 14,15 . Our study aims to calculate the coiling index and its association with foetal outcome.

\section{Materials and methods}

It's a prospective study done in the department of Obstetrics and Gynaecology from January 2019 to June 2019 after obtaining the institutional ethical clearance and including the cases after taking informed consent from them. Total of 600 cases admitted to our labour ward with 28-40 weeks of gestational age, singleton pregnancy with no known foetal anomalies were included in the study. Whereas multiple pregnancies with known congenital anomalies were excluded from the study. The cases undergoing both vaginal delivery and elective or emergency caesarean section were included in the study.

Immediately following the delivery of the baby, the cord was clamped leaving about $5 \mathrm{~cm}$ on the foetal side. After the complete separation of the placenta, the remaining length of the cord from the junction cut to the placental insertion was measured and the $5 \mathrm{~cm}$ of length left behind with baby was added to it. The number of coils, defined as the $360^{\circ}$ complete spiral course of umbilical vessels around Walton's jelly were counted. The coiling index was calculated by the total number of coils divided by the total length of the cord in cms. The parameters like a vaginal delivery, instrumental deliveries, caesarean section, abnormal foetal heart rate, abnormal liquor, associated medical disorders like hypertension in pregnancy, gestational diabetes mellitus, abruption placenta, low birth weight, low Apgar score and perinatal mortality and their association with the coiling index were assessed. The cases were assessed as per the above mentioned parameters by dividing them into hypocoiled, normocoiled and hypercoiled groups. The Data was analysed using the chi-square test, Fisher's exact test and student ' $t$ ' test. Statistical analysis was said to be significant if $p$-value $<0.05$.

\section{Results}

Total 600 cases were included in the study. The mean length of the cord was $56.1 \pm 15.9 \mathrm{~cm}$, the mean number of Table 1: Umbilical coil characteristics

\begin{tabular}{|c|c|c|c|c|}
\hline $\begin{array}{l}\text { Umbilical coil } \\
\text { characteristics }\end{array}$ & Number & Minimum & Maximum & Mean \pm SD \\
\hline Length & 600 & 30 & 100 & $56.1 \pm 15.9$ \\
\hline Number of coils & 600 & 4 & 36 & $31.0 \pm 9.8$ \\
\hline $\mathrm{cms}$ ) & 600 & 0.07 & 0.64 & $0.57 \pm 0.18$ \\
\hline
\end{tabular}


coils was $31.0 \pm 9.8$ and the mean umbilical coiling index was $0.57 \pm 0.18$ per $\mathrm{cm}$ (Table 1$)$.

In our study, the caesarean section rate was $53.3 \%$ in deliveries were in normocoiled group with $70.66 \%$, when compared to hypocoiled and hypercoiled group with $23.33 \%$ and $4.6 \%$ respectively with statistical significance. Table 2
Table 2: Distribution of cases in 3 groups according intrapartum factors

\begin{tabular}{|c|c|c|c|c|}
\hline $\begin{array}{l}\text { Umbilical } \\
\text { coiling } \\
\text { index }\end{array}$ & $\begin{array}{l}\text { Normal fetal heart } \\
\text { rate } \\
n=448\end{array}$ & $\begin{array}{l}\text { Abnormal fetal } \\
\text { heart } \\
n=152\end{array}$ & $\chi^{2}$ value & P value \\
\hline Hypocoiled & $100(22.32 \%)$ & $40(26.31 \%)$ & & \\
\hline Normocolied & $318(70.98 \%)$ & $80(52.63 \%)$ & 29.2 & $<0.001 *$ \\
\hline Hypercoiled & $30(6.69 \%)$ & $32(20.77 \%)$ & & \\
\hline $\begin{array}{l}\text { Umbilical } \\
\text { coiling } \\
\text { index }\end{array}$ & $\begin{array}{l}\text { Normal } \\
\text { liquor } \\
n=494\end{array}$ & $\begin{array}{l}\text { Abnormal } \\
\text { liquor } \\
\mathrm{n}=106\end{array}$ & & \\
\hline Hypocoiled & $96(19.43 \%)$ & $44(41.50 \%)$ & & \\
\hline Normocolied & $343(69.43 \%)$ & $55(51.88 \%)$ & 31.8 & $<0.001 *$ \\
\hline Hypercoiled & $39(7.8 \%)$ & $23(21.69 \%)$ & & \\
\hline $\begin{array}{l}\text { Umbilical } \\
\text { coiling } \\
\text { index }\end{array}$ & $\begin{array}{l}\text { Spontaneous } \\
\text { vaginal delivery } \\
n=450\end{array}$ & $\begin{array}{l}\text { Caesarean } \\
\text { section } \\
n=150\end{array}$ & & \\
\hline Hypocoiled & $105(23.33 \%)$ & $35(23.3 \%)$ & & \\
\hline Normocolied & $318(70.66 \%)$ & $80(53.3 \%)$ & 59.2 & $<0.001^{*}$ \\
\hline Hypercoiled & $21(4.6 \%)$ & $41(27.33 \%)$ & & \\
\hline
\end{tabular}

Table 3: Distribution frequencies of the three groups according to postnatal factors

\begin{tabular}{|c|c|c|c|c|}
\hline $\begin{array}{l}\text { Umbilical } \\
\text { coiling index }\end{array}$ & $\begin{array}{l}\text { Normal apgar } \\
\mathbf{n}=\mathbf{5 0 0}\end{array}$ & $\begin{array}{l}\text { Low apgar } \\
n=100\end{array}$ & $\chi^{2}$ value & p value \\
\hline Hypocoiled & $114(22.8 \%)$ & $26(26 \%)$ & & \\
\hline Normocoiled & $338(67.6 \%)$ & $60(60 \%)$ & 6.002 & 0.050 \\
\hline Hypercoiled & $45(9 \%)$ & $17(17 \%)$ & & \\
\hline $\begin{array}{l}\text { Umbilical } \\
\text { coiling index }\end{array}$ & $\begin{array}{l}\text { Normal birth weight } \\
n=540\end{array}$ & $\begin{array}{l}\text { Low birth weight } \\
n=60\end{array}$ & & \\
\hline Hypocoiled & $97(17.96 \%)$ & $43(71.66 \%)$ & & \\
\hline Normocoiled & $368(68.14 \%)$ & $30(50 \%)$ & 47.2 & $<0.001 *$ \\
\hline Hypercoiled & $50(9.2 \%)$ & $12(20 \%)$ & & \\
\hline
\end{tabular}

Note: ${ }^{*}$ Significant at $5 \%$ level of significance $(\mathrm{p}<0.05)$ also showed the association between hypocoiled, normocoiled and hypercoiled with abnormal foetal heart rate i.e. $26.31 \%, 52.63 \%$, $20.77 \%$ respectively with the $\mathrm{p}$ value of $<0.001$ which is highly significant. Hypocoiled and normocoiled were associated with meconium stained liquor when compared to hypercoiled as in table 2 , which is statistically significant. Our study showed a significant association of low birth weight in hypocoiled group with $71.66 \%$ in comparison with normocoiled and hypercoiled group with statistical significance as shown in table 3 . But their was no significant association of low APGAR score when compared with hypocoiled, normocoiled and hypercoiled groups (Table -3). Even though in our study, more cases were seen in normocoiled group. The association of medical disorders like hypertension and diabetes mellitus were more in hypocoiled group in comparison to hypercoiled group as shown in table 4 with statistical

Table 4: Different antenatal complications

\begin{tabular}{llllll}
\hline Maternal complications & Normocoiled & Hypocoiled & Hypercoiled & $\chi^{2}$ value & P value \\
\hline Hypertensive disorders & $90(22.61 \%)$ & $36(25.71 \%)$ & $6(9.6 \%)$ & 190.2 & $<0.001^{*}$ \\
Gestational diabetes & $67(16.83 \%)$ & $22(15.71 \%)$ & $9(14.5 \%)$ & 135.9 & $<0.001^{*}$ \\
Oligohydromnios & $86(21.6 \%)$ & $16(11.42 \%)$ & $2(3.22 \%)$ & 247.8 & $<0.001^{*}$ \\
Polyhydromnios & $55(13.81 \%)$ & $14(10 \%)$ & $9(14.5 \%)$ & 117.3 & $<0.001^{*}$ \\
Non-reassuring FHR & $80(20.10 \%)$ & $40(28.57 \%)$ & $32(51.6 \%)$ & 146.7 & $0.001^{*}$ \\
Placental abruption & $13(3.26 \%)$ & $8(5.71 \%)$ & $2(3.22 \%)$ & 14.9 & $<0.001^{*}$ \\
Intrauterine fetal death & $7(1.75 \%)$ & $4(2.85 \%)$ & $2(3.22 \%)$ & 8.16 & $0.017^{*}$ \\
\hline
\end{tabular}

Note: ${ }^{*}$ Significant at $5 \%$ level of significance $(\mathrm{p}<0.05)$

normocoiled group and was significantly higher in hypercoiled group when compared with hypocoiled group with $27.33 \%$ and $23.3 \%$ respectively (Table 2). Our study also showed that highest number of spontaneous vaginal significance. Similarly, obstetric complications like oligohydramnios, polyhydramnios and abruptio placenta were more in hypocoiled group in comparison with hypercoiled group as in table 4 . Non-reassuring foetal heart 
rate and intrauterine death were also more in hypocoiled group than hypercoiled group as in table 4.

\section{Discussion}

The umbilical cord and its vital blood vessels are the most vulnerable part of the foetal anatomy. The total number of coils for any particular cord is believed to be established early in the gestation ${ }^{16,17}$. The role of umbilical cord coiling is not clear, nonetheless, it is thought to play a role of protecting the umbilical cord from external forces such as tension, pressure, stretching or entanglement ${ }^{18,19}$. The aim of our study was to know the relationship between abnormal coiling index and various maternal and perinatal complications. There are several studies done to know the correlation between the length of the umbilical cord and coiling index and its association with the perinatal outcome. The mean umbilical coiling index (UCI) in our study is $0.57 \pm 0.18 \mathrm{~cm}$, which is comparable with study by Enas Adnan et.al (2014) ${ }^{12}$ and T. Chitra et al (2012) ${ }^{11}$, whereas the length was less compared to study by Nilesh et al (2012) ${ }^{2}$. There are studies showing difference between the UCI measured antenatally and that at birth, thus explaining sampling error of different umbilical cord segments with discordant coiling pattern or dynamically evolving UCI with advancing gestational age ${ }^{20}$.

In our study, the abnormal FHR variations were found to have significant association with both hypocoiled and hypercoiled groups. Literature has found a consistent association between intrapartum FHR decelerations and abnormal UCI. Strong et al ${ }^{21}$ and de Laat el al ${ }^{22}$ found that FHR decelerations are associated with both hypocoiled and hypercoiled cords. The possibility of the undercoiled cords may be more susceptible to acute kinking and there by abrupt and marked cessation of blood flow. In cases of hypercoiled cords, flow dynamic principles and studies may suggest that flow through a coiled tube should be associated with greater resistance to flow than through a straight tube ${ }^{23}$. Meconium staining of the amniotic fluid was found to have a significant association with both hypocoiled $(\mathrm{p}<.001)$ and hypercoiled $(\mathrm{p}<0.001)$. This finding was similar to those noted in studies done by Strong et al ${ }^{22}$ and Ezimokhai et al ${ }^{24}$, although they didn't offer a specific explanation for this observation.

Though many studies have shown that meconium staining of liquor and intrauterine foetal death are associated more in hypercoiled group, but in our study, they were more associated with hypocoiled group. This may be attributed to acute kinking and therefore abrupt hypoxia in the foetus.
In our study, low birth weight was found significantly associated with hypocoiled group but many other studies done showed that hypercoiled are associated with LBW babies, as shown by Rana et al ${ }^{25}$, Raio et al ${ }^{26}$ and de Laat et $\mathrm{al}^{27}$. However clear explanation for the same was not given.

Hypertensive disorders of pregnancy was found to be significantly associated with hypocoiled (25.71\%) than hypercoiled, this was similar to study by Ezimokhai et al. ${ }^{24}$ and Gupta et al ${ }^{6}$. The coiled umbilical cord, because of its elastic properties, is able to resist external forces that might compromise the umbilical vascular flow. The coiled umbilical cord actslike a semi erectile organ that is more resistant to snarling torsion, stretch, and compression than the noncoiled one ${ }^{6,16}$. This might explain the association of hypocoiling with preeclampsia.

In our study, diabetes mellitus was found to be significantly associated with hypocoiled (15.71\%) in comparison with hypercoiled group. Study done by Chitra et al. ${ }^{10}$ showed association of GDM more in hypercoiled group. Ezimokhai et al. ${ }^{24}$, however, found significant association of GDM with both hypocoiled and hypercoiled. The limitations of our study was that the UCL was not measures antenatally and the sample size is less in hypercoiled and hypocoiled group to conclude the outcomes based on them.

To conclude, abnormal umbilical coiling index is associated with several adverse antenatal and neonatal features. The association shows wide variations among the various studies done so far. Antenatal study of UCI should be further pursued to confirm diagnosis at an earlier gestational age.

\section{Conclusion}

The present study showed that even though the length of umbilical cord is variable, still the maximum number of cases had normal cord length. Abnormal cord length constituted both short and long cords. These cases were associated with higher incidence of cord complications, increased incidence of operative interference, intrapartum complications, increased foetal heart rate abnormalities and more chances of birth asphyxia. Thus, implying the importance of the knowledge of cord length. The findings of abnormal foetal heart rate and failure of descent of the foetus during labour is not uncommon. To analyse cord complications during intrapartum period and antenatally strategies have to be formed at the institutional levels to bring down the rate of perinatal mortality.

Thus, this study would emphasise the protocol for detection of abnormal UCI and be vigilant in such cases to 
The New Indian Journal of OBGYN. 2020 (July-December); 7(1)

decrease the incidences of the perinatal morbidity and mortality due to cord complications in the future, and help in realizing the exceptions for the delivery of a healthy baby.

\section{Acknowledgement}

I would like to acknowledge Mr. Shahnawaz, $\mathrm{PhD}$ Statistician, department of Statistics BLDE (Deemed to be) University, Shri.B.M.Patil Medical College, Vijayapura for helping me throughout the study.

\section{Conflict of interest: None. Disclaimer: Nil.}

\section{References}

1. Misra R, editor. Ian Donald's Practical obstetric problems. Gurugram: Wolters Kluwer; 1994: p.417.

2. Unmesh BN, Ashok SM. Study of Length Of Umbilical Cord and Fetal outcome: A study Of 1,000 Deliveries. J of Obstetrics and Gynaecology of India. 2012; 62(5): 520-5.

3. Chaurasia BD, Agarwal BM. Helical structure of the human umbilical cord. Acta Anatomica. 1979; 103(2): 226-30.

4. Lacro RV, Jones KL, Benirschke K. The umbilical cord twist: origin, direction, relevance. American Journal Of Obstetrics and Gynecology. 1987; 157(4): 833-8.

5. Patil NS, Kulkarni SR, Lohitashwa R. Umblical cord coiling index and perinatal outcome. Journal of Clinical and Diagnostic Research. 2013; 7(8): 1675-7.

6. Gupta S, Faridi MMA, Krishnan J. Umblical coiling index. The Jounal Of Obstetrics and Gynecology of India. 2006; 56(4):315-9.

7. Predanic M, Perni SC, Chasen ST, Baregen RT, Chervanak FA. Ultrsound evaluation of abnormal umblical cord coiling in second trimester of gestation in association with adverse pregnancy outcome. American Jounal of Obstetrics and Gynecology. 2005; 193(2): 387-94.

8. Cunningham FG, Leveno KG, Bloom SL, Hauth JC, Roves DJ, Spong CY, editors. William's Obstetrics. 24th edition. New York: MC Graw Hill; 2014. p.116-25.

9. Soliriya V, Goyal M, Kachhawaha CP. Perinatal Mortality and Umbilical Cord Parameters: Is there Any Association? Journal of Pregnancy and Child Health. 2017. 4: 340 .

10. Chitra T, Sushanth YS, Raghavan S. Umbilical Coiling Index as a Marker of Perinatal Outcome: An Analytical Study. Hindawi Publishing Corporation Obstetrics and
Gynaecology International. 2012; 2012: Article ID 213689.

11. Abdulrasul EA. Umbilical coiling index as a predictor of adverse perinatal outcome. International Journal of Advanced Research. 2014; 2(2): 101-7.

12. Gupta S, Faridi MMA, Krishnan J. Umbilical Coiling Index. J Obstet Gynecol India. 2006; 56(4); 315-9.

13. Edmonds HW. The spiral twists of the normal umbilical cord in twins and in singletons. Am J Obstet Gynecol. 1954; 67: 102-20

14. Yun Sung J, Dong K J, Guisera L. The Sonographic Umbilical Cord Coiling in Late Second Trimester of Gestation and Perinatal Outcomes. International Journal of Medical Sciences. 2011; 8(7): 594-8.

15. Jang DG, Jo YS, Lee SJ, Kim N, Lee GS. Perinatal outcomes and maternal clinical characteristics in IUGR with absent or reversed end-diastolic flow velocity in the umbilical artery. Arch Gynecol Obstet. 2011; 284(1): 73-8.

16. Machin GA, Ackermann J, Gilbert Barness E. Abnormal umbilical cord coiling is associated with adverse perinatal outcomes. Pediatr Dev Pathol. 2000; 3(5): 462-71.

17. van Dijk CC, Franx A, De Latt MWM, Bruinse HW, Visser GHA, Nikkels PGJ. The umbilical coiling index in normal pregnancy. J Matern Fetal Neonatal Med. 2002; 11(4): 280-3.

18. Kwon JY, Jo YS, Lee GS, Kim SJ, Shin JC, Lee Y. Cervical dilatation at the time of caesarean section may affect the success of a subsequent vaginal delivery. J Matern Fetal Neonatal Med. 2009; 22: 1057-62.

19. Nam SW, Jo YS, Eun JW, Song JY, Ryu KS, Lee JY, et al. Identification of large scale characteristic genes of Mullerian inhibiting substance in human ovarian cancer cells. Int J Mol Med. 2009; 23(5): 589-96.

20. Predanic M, Perni SC, Chasen ST, Baergen RN, Chervenak FA. Ultrasound evaluation of abnormal umbilical cord coiling in second trimester of gestation is associated with adverse pregnancy outcome. Am J Obstet Gynecol. 2005; 193(2): 387-94.

21. Strong TH, Elliot JP, Radin TG. Noncoiled umbilical blood vessels: A new marker for the fetus at risk. Obstet Gynecol. 1993; 81: 409-11

22. de Laat MW, Franx A, van Alderen ED, Nikkels PGJ, Visser GHA. The umbilical coiling index, a review of the literature. J Matern Fetal Neonatal Med. 2005; 17(2): 93-100. 
The New Indian Journal of OBGYN. 2020 (July-December); 7(1)

23. Garber A, Hernandez L, Mullin C, Simon M. Pressure Flow Through a Coiled Tube, Group M5, BE 310 Spring 2004; http://www.seas.upenn.edu/courses/belab/ LabProjects/2004/ be310s04m5.doc [Accessed 23 August 2007].

24. Ezimo Khai M, Rizk DEE, Thomas L. Maternal Risk Factors for Abnormal Vascular Coiling of the Umbilical Cord. Am J. Perinat. 2000: 17(8): 441-5.

25. Rana J, Ebert GA, Kappy KA. Adverse Perinatal Outcome in Patients with an abnormal Umbilical Coiling Index Am J. Obstet Gynaecol. 1995; 85(4): 573-7.

26. Raio L, Ghezzi F, Di Naro E, Franchi M, Maymon E, Mueller MD, et al. Prenatal Diagnosis of a lean
Umbilical Cord: A Simple Marker of the Fetuses at Risk. Ultrasound Obstet Gynecol. 1999; 13(3):157-60.

27. de Laat MW, van Alderen ED, Franx A, Visser GH, Bots ML, Nikkels PG. The Umbilical Coiling Index in Complicated Pregnancy. Eur J. Obstet Reprod Biol. 2007; 130(1): 66-72.

Aruna Biradar ${ }^{1}$, Shreedevi Kori ${ }^{2}$, Neelamma Patil $^{3}$, SR Mudanur 4

${ }^{1}$ Associate Professor; ${ }^{2}$ Associate Professor; ${ }^{3}$ Associate Professor; ${ }^{4}$ Associate professor, Department of

Obstetrics and Gynaecology, BLDE (Deemed to be) Shri BM Patil Medical College Hospital Research Center, Vijayapura, Karnataka, India. 